\title{
Valve performance classification in 630 subcoronary Ross patients over 22 years
}

\author{
Hans-Hinrich Sievers, MD, ${ }^{a}$ Ulrich Stierle, MD, ${ }^{a}$ Michael Petersen, MD, ${ }^{a}$ Stefan Klotz, MD, ${ }^{a}$ \\ Doreen Richardt, MD, ${ }^{a}$ Michael Diwoky, ${ }^{a}$ and Efstratios I. Charitos, MD, $\mathrm{PhD}^{\mathrm{b}}$
}

\section{ABSTRACT}

Objective: To define the function of the "Ross valves" and its clinical meaning in a practical valve performance classification as part of the outcome analysis.

Methods: From 1994 to 2017, 630 consecutive patients underwent the subcoronary Ross procedure at our institution. The valve performance classification combines hemodynamics, symptoms, and management criteria. Median follow-up was 12.5 years (maximum 22.3 years, 7404 patient-years, 99.4\% completeness).

Results: The mean age of the patients was $44.7 \pm 11.9$ years. Hospital deaths was $0.3 \%(\mathrm{n}=2)$. Twenty years after the operation survival was $73.1 \%(95 \%$ confidence interval $[\mathrm{CI}], 65.4 \%-81.6 \%$ ) and statistically not different from the ageand gender-matched general population; freedom from reoperation was $85.9 \%$ (95\% CI, 80.2\%-92.0\%; 0.6\% per patient-year), 89.8\% (95\% CI, 84.3\%$95.7 \%$ ) for autograft, and $91.0 \%$ (95\% CI, 86.3\%-96.0\%) for homograft. Preoperative annulus diameter, aortic regurgitation, annulus reinforcement, sinotubular junction reinforcement, and bicuspid aortic valve type were no significant risk factors for reoperation. At 20 years the probability of a patient being in valve performance class I to IV was $5 \%, 74 \%, 19 \%$, and $1 \%$, respectively. Time to reoperation was not different in bicuspid and tricuspid aortic valves; preoperative aortic stenosis tended to have better outcome of autograft function.

Conclusions: These up to 22 years data show that the subcoronary Ross procedure continues to provide an excellent tissue aortic valve replacement. The suggested valve performance classification emerged as a practical concept for outcome analysis with the probability of $79 \%$ being in the favorable class I or II at 20 years. ( $\mathrm{J}$ Thorac Cardiovasc Surg 2018;156:79-86)

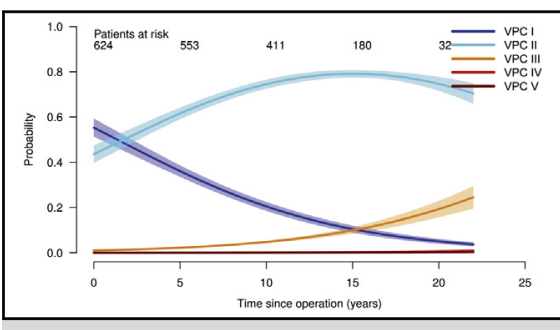

Valve performance classes over time after the subcoronary Ross procedure.

\section{Central Message}

Up to 22 years the subcoronary Ross procedure provides excellent results. A valve performance classification emerged as a practical concept for outcome analysis.

\section{Perspective}

The presented valve performance classification might surface as a practical tool to analyze different Ross techniques and other valve substitutes. The subcoronary Ross technique includes the native aortic root as a natural dynamic external reinforcement with favorable effects on preventing root dilatation and potentially preserving autograft function, a principle that needs further evaluation.

See Editorial Commentary page 87.

See Editorial page 77
Life after replacement of the aortic valve is still subjected to certain prosthesis-related shortcomings. Several replacement substitutes are available for different patient conditions. For decision-making, detailed information on

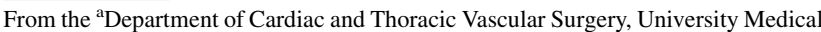
Center Schleswig-Holstein, Campus Lübeck, Germany; and ${ }^{\mathrm{b}}$ Department of Cardiac Surgery, Halle-Wittenberg University, Halle (Saale), Germany.

Received for publication Oct 25, 2017; revisions received Jan 30, 2018; accepted for publication March 5, 2018; available ahead of print March 29, 2018.

Address for reprints: Hans-Hinrich Sievers, MD, Department of Cardiac and Thoracic Vascular Surgery, University Medical Center Schleswig-Holstein, Ratzeburger Allee 160, 23538 Luebeck, Germany (E-mail: Hans-Hinrich.Sievers@uksh.de). $0022-5223 / \$ 36.00$

Copyright $(2018$ by The American Association for Thoracic Surgery https://doi.org/10.1016/j.jtcvs.2018.03.015
}

survival, valve performance, and adverse events is essential. These 3 components mainly influence clinical status and quality of life or life satisfaction. Grading of valve hemodynamics from normal function, over different degrees of dysfunction to reoperation and combining it with symptoms and management allows for creating a valve performance classification (VPC). More recently echocardiographic

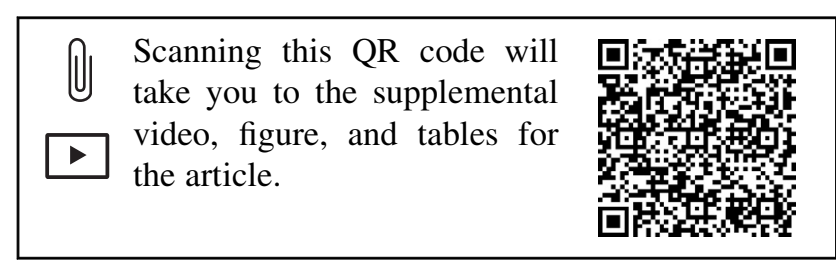




\section{Abbreviations and Acronyms \\ $\mathrm{BAV}=$ bicuspid aortic valve \\ $\mathrm{CI}=$ confidence interval \\ $\mathrm{VPC}=$ valve performance classification}

associations have defined several levels of valve function concerning stenosis and regurgitation, ${ }^{1,2}$ paving the way for our new VPC that combines grading of valve function with valve-related symptoms and management according to recent guidelines. ${ }^{3}$ This VPC has the aim to provide a practical and lucid tool for a more differentiated judgement of the Ross and other surgical valve procedures, for better scientific and clinical communication and more detailed information.

The Ross procedure is the only aortic valve replacement method using autologous, living semilunar valve tissue, and as such has a promising potential for a permanent near physiological valve replacement. There is now clinical evidence that the Ross procedure in the young and middle-aged patients is associated with excellent outcome. ${ }^{4-10}$ Long-term results are growing for the freestanding or inclusion technique ${ }^{11-13}$ but are scarce for the original subcoronary technique. Furthermore, there is a lack of a practical VPC for comparison between different techniques and substitutes. Therefore we introduced a new VPC as part of the overall outcome evaluation in 630 consecutive Ross patients using the subcoronary technique over the past 22 years.

\section{METHODS \\ Patients}

Six hundred thirty subcoronary Ross patients were consecutively operated on between June 1994 and January 2017 in the Department of Cardiac and Thoracic Vascular Surgery of the University Medical Center Schleswig-Holstein, Campus Lübeck (Lübeck, Germany) and were included in the study. Thirty-three patients who received surgery with the root inclusion technique were included in the study group because there was no difference between the root inclusion technique and the subcoronary technique in former studies. ${ }^{8,14,15}$ The indication for the aortic valve operation and reoperation was in accordance with the American Heart Association/American College of Cardiology guidelines. ${ }^{16}$ These Ross patients constitute a selected patient group because patients with significantly reduced left ventricular function, coronary artery disease in more than 1 vessel, connective tissue disorders and active rheumatic disease, severe deformation of the aortic root, and pulmonary valve abnormalities or uncontrolled hypertension were exclusion criteria for the Ross procedure. Four hundred eighty-four patients with bicuspid aortic valve (BAV) of the different types ${ }^{17}$ were included. The postoperative medication consisted of clopidogrel $75 \mathrm{mg} / \mathrm{d}$ for 3 months and ibuprofen $400 \mathrm{mg} / \mathrm{d}$ for 5 weeks and lifelong blood pressure regulation.

\section{Surgical Technique}

The surgical technique (Video 1) has been described in detail previously. ${ }^{18}$ In brief: standard cardiopulmonary bypass and moderate systemic hypothermia of $28^{\circ} \mathrm{C}$ was performed. After crystalloid cardioplegia in the first years, blood cardioplegia at 20-minute intervals has been used in the

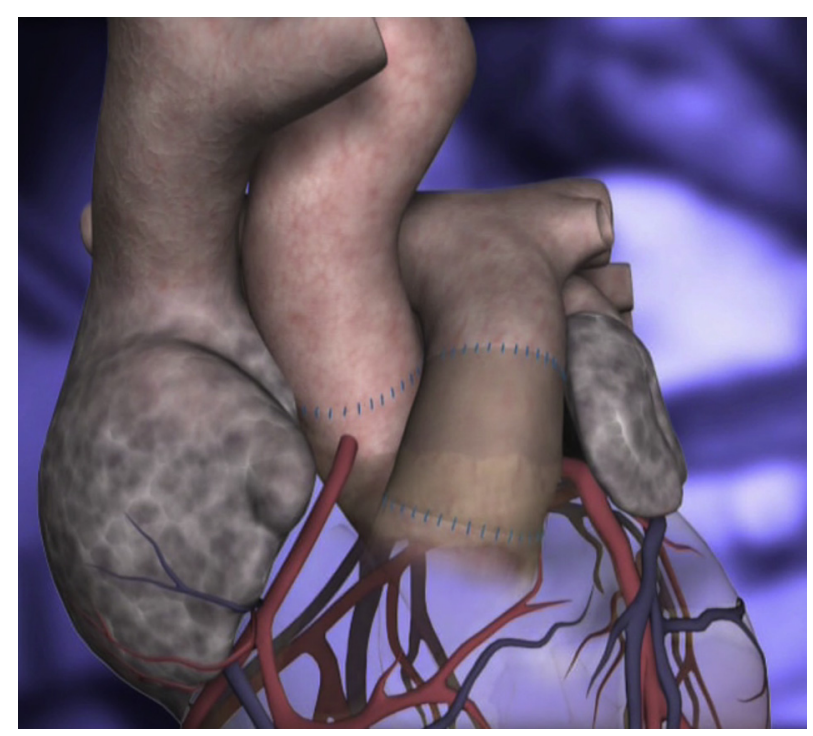

VIDEO 1. The subcoronary Ross procedure. Video available at: http:// www.jtcvsonline.org/article/S0022-5223(18)30726-8/fulltext.

past 15 years. The proximal autograft anastomosis was performed using a single suture technique (4/0 multifilament suture). The sinus suture was performed continuously with $5 / 0$ prolene and additionally $5 / 0$ prolene U-stitch was used to fix the commissures to the aortic wall of the patient. The sinus wall directed to the noncoronary sinus of the patient was left in toto. In BAV type 1 and 2 the autograft implantation technique was similar to that for the tricuspid valves, because in those BAV types there are 3 sinuses and 3 commissures. ${ }^{17}$ The geometry of the autograft, which was in these cases often somewhat asymmetrical was adapted to the aortic root anatomy, meaning that the largest sinus of the autograft was placed in the largest sinus of the aortic root mostly the noncoronary artery. In type $0 \mathrm{BAV}$, a new commissure for the autograft was created between the $180^{\circ}$ coronary orifices, normally on the left lateral aortic root aspect and the other commissures of the autograft were fixed on the right site of the root and coronary ostia so that the autograft geometry was preserved as much as possible. The homograft was implanted distally and proximally with $5 / 0$ prolene continuously. The ascending aorta was replaced or reduced in sized by aortoplasty as described recently. ${ }^{19}$

\section{Follow-up}

The study was approved by the local ethics committee (Clinical Trials ID: NCT00708409). Follow-up was performed on an annual basis using standard echocardiography and clinical evaluation. ${ }^{8,20,21}$ The median follow-up time was 12.5 years $(95 \%$ confidence interval [CI], 11.9-13.1 years, range 0-22.3 years, 7404 patient-years, follow-up completeness, 99.4\%). Patient demographic characteristics and preoperative and operative data are shown in Table 1 and Table E1. A total of 7201 clinical follow-up visits were performed, 6668 of these included echocardiographic examination. The completeness of echocardiographic follow-up is depicted in Table E2.

\section{Valve Performance Classification}

The VPC is shown in Table 2. Current echocardiographic recommendations were used for the grading of valve stenosis ${ }^{2}$ and regurgitation severity. ${ }^{1}$ Furthermore, the presence of symptoms was included. In an individual patient the worst single hemodynamic parameter regardless of whether it was related to homograft or autograft determined the VPC. 
TABLE 1. Patient demographic and preoperative data

\begin{tabular}{|c|c|}
\hline & Value \\
\hline Subcoronary patients & $630(100)$ \\
\hline \multicolumn{2}{|l|}{ Gender } \\
\hline Male & $472(74.9)$ \\
\hline Female & $158(25.1)$ \\
\hline Age, y & $44.7 \pm 11.9$ \\
\hline \multicolumn{2}{|l|}{ Age group, y } \\
\hline$<20$ & $20(3.2)$ \\
\hline 20 to 40 & $188(29.8)$ \\
\hline 40 to 60 & $372(59.0)$ \\
\hline$>60$ & $50(7.9)$ \\
\hline \multicolumn{2}{|l|}{ NYHA } \\
\hline Class I & $182(28.9)$ \\
\hline Class II & $337(53.5)$ \\
\hline Class III & $108(17.1)$ \\
\hline Class IV & $3(0.5)$ \\
\hline \multicolumn{2}{|l|}{ Ejection fraction, $\%$} \\
\hline$>50$ & $575(91.3)$ \\
\hline 30 to 50 & $54(8.6)$ \\
\hline$<30$ & $1(0.2)$ \\
\hline Diabetes mellitus & $29(4.6)$ \\
\hline Hypertension & $203(32.2)$ \\
\hline Impaired renal function & $34(5.4)$ \\
\hline \multicolumn{2}{|l|}{ Rhythm } \\
\hline Sinus & $622(98.7)$ \\
\hline Atrial fibrillation & $7(1.1)$ \\
\hline Pacemaker & $1(0.2)$ \\
\hline \multicolumn{2}{|l|}{ Aortic valve hemodynamics } \\
\hline Pure regurgitation & $154(24.4)$ \\
\hline Pure stenosis or combined lesion & $475(75.4)$ \\
\hline \multicolumn{2}{|l|}{ Aortic valve morphology } \\
\hline Tricuspid & $132(21.2)$ \\
\hline Bicuspid & $484(77.7)$ \\
\hline Type 0 & $22(5.4)$ \\
\hline Type 1 & $259(63.2)$ \\
\hline Type 2 & $129(31.5)$ \\
\hline Unknown & 74 \\
\hline Other & $7(1.1)$ \\
\hline Unknown & 7 \\
\hline \multicolumn{2}{|l|}{ Etiology } \\
\hline Congenital & $466(74.0)$ \\
\hline Degenerative & $288(45.7)$ \\
\hline Myxomatous & $76(12.1)$ \\
\hline Rheumatic & $6(1.0)$ \\
\hline Active endocarditis & $26(4.1)$ \\
\hline Past endocarditis & $120(19.0)$ \\
\hline Annulus diameter, mm & $25.3 \pm 4.3$ \\
\hline Sinus diameter, mm & $33.4 \pm 5.2$ \\
\hline Sinotubular junction diameter, mm & $29.6 \pm 5.6$ \\
\hline Ascending aorta diameter, $\mathrm{mm}$ & $39.1 \pm 7.6$ \\
\hline
\end{tabular}

The clinical relevance or management was adapted from the 2017 European Society of Cardiology and European Association for Cardio-Thoracic Surgery guidelines for the management of valvular heart disease.

\section{Statistical Analysis}

The data were expressed as absolute and relative frequencies in nominal and ordinal data and as mean \pm SD in continuous data. Median follow-up time was calculated using the reverse Kaplan-Meier approach and the follow-up completeness using the method of Clark and colleagues. ${ }^{22}$ The probability of survival and freedom from reoperation were calculated using the Kaplan-Meier method. The long-term survival was compared with age- and gender-matched German general population data (German Life Tables; available at: http://www.destatis.de). The instantaneous risk for reoperation was calculated for autograft, homograft, and autograft + homograft. The longitudinal evaluation of echocardiographic and VPC data was performed using multivariate mixed-model regression for continuous data and extensions of mixed-models for ordinal data allowing for random patient intercept and slope. These analyses consider only patients who were alive and were not adjusted for the competing risk of death. To identify the predictive variables for time to event outcomes we performed univariate analyses using the Cox proportional hazard regression model. Multivariate Cox proportional hazard models were used to confirm whether significant $(P<.10)$ univariate predictors persisted in the presence of other preoperative variables. The following factors were analyzed as potential risk factors for autograft or homograft reoperation age, year of surgery, gender, presence of comorbidities (eg, diabetes, hypertension, renal failure, coronary artery disease, pulmonary disease, peripheral vascular disease), previous cardiac surgery, preoperative hemodynamics, aortic valve and root morphology (annulus diameter, preoperative aortic regurgitation, annulus reinforcement, sinotubular junction reinforcement, BAV type) year of surgery, as well as homograft donor parameters (eg, diameter, donor recipient age, and blood group mismatch).

A $P$ value $<.05$ was considered significant. All data were analyzed with the use of $\mathrm{R}$ ( $\mathrm{R}$ Core Team, 2017. R: A language and environment for statistical computing, R Foundation for Statistical Computing, Vienna, Austria; https://www.R-project.org).

\section{RESULTS \\ Survival}

At 30 days, all-cause mortality was $0.3 \%(n=2)$. Long-term survival rate at $5,10,15$, and 20 years after the surgery was $97.8 \%(95 \% \mathrm{CI}, 96.6 \%-99.0 \%)$, $95.1 \% \quad(95 \% \quad$ CI, $93.3 \%-96.9 \%), \quad 86.8 \% \quad(95 \% \quad$ CI, $83.3 \%-90.5 \%$ ) , and $73.1 \%$ (95\% CI, 65.4\%-81.6\%) and not different from the age- and gender-matched general German population (Figure 1). The freedom from cardiac death was $99.3 \%(95 \%$ CI, 98.7\%-100\%), 98.1\% (95\% CI, $97.0 \%-99.3 \%), 94.8 \%(95 \%$ CI, $92.5 \%-97.2 \%)$, and $86.4 \%(95 \% \mathrm{CI}, 79.1 \%-94.3 \%)$ at $5,10,15$, and 20 years, respectively. There was 1 cardiac death 11 days after autograft reoperation due to endocarditis and 1 patient died during transcatheter homograft replacement due to major bleeding.

\section{Reoperation}

Freedom from reoperation and instantaneous risk for reoperation are depicted in Figures 2 and 3. 
TABLE 2. Valve performance classification

\begin{tabular}{|c|c|c|c|c|}
\hline \multirow[b]{2}{*}{ Class } & \multicolumn{2}{|c|}{ Hemodynamic parameters } & \multirow{2}{*}{$\begin{array}{l}\text { Valve-related } \\
\text { symptoms }\end{array}$} & \multirow[b]{2}{*}{ Management $\dagger$} \\
\hline & Stenosis & Regurgitation* & & \\
\hline I (normal/near normal) & $\begin{array}{l}\text { MG: }<10 \\
\text { PV: } \leq 2.5\end{array}$ & None, trace & None & $\begin{array}{l}\text { Reevaluation on the discretion of the physician, preferable } \\
\text { yearly }\end{array}$ \\
\hline II (mild dysfunction) & $\begin{array}{l}\text { MG: } 10 \text { to } 19 \\
\text { PV: } 2.6 \text { to } 2.9 \\
\text { AVA: }>1.5\end{array}$ & Mild (grade I) & None & Clinical and echocardiography exam yearly \\
\hline \multirow[t]{2}{*}{ III (moderate dysfunction) } & $\begin{array}{l}\text { MG: } 20 \text { to } 40 \\
\text { PV: } 3.0 \text { to } 4.0 \\
\text { AVA: } 1.0 \text { to } 1.5\end{array}$ & Moderate (grade II) & None & $\begin{array}{l}\text { Close follow-up. Consider reoperation in case of CABG, aortic } \\
\text { or other cardiac valve surgery (IIa) }\end{array}$ \\
\hline & & & Symptoms & Consider reoperation in patients with low flow-low gradient (Ia) \\
\hline \multirow[t]{2}{*}{ IV (severe dysfunction) } & $\begin{array}{l}\text { MG: } \geq 40 \\
\text { PV: } \geq 4.0 \\
\text { AVA: }<1.0\end{array}$ & $\begin{array}{l}\text { Severe } \\
\text { (grade III, IV) }\end{array}$ & None & $\begin{array}{l}\text { Consider reoperation } \\
\text { - For AS: } \\
\circ \mathrm{EF}<50 \% \text { (I) } \\
\circ \text { Abnormal exercise test (symptoms [I], increase of mean } \Delta \\
P>20 \mathrm{~mm} \mathrm{Hg}[\mathrm{IIb}] \text {, decrease in blood pressure [IIa]) } \\
\circ \text { Excessive LV hypertrophy in absence of hypertension } \\
\text { (IIb) } \\
\circ \text { Undergoing CABG, aortic, or other cardiac valve surgery } \\
\text { (I) } \\
\text { Normal EF but peak transvalvular velocity }>5.5 \mathrm{~m} / \mathrm{s}(\mathrm{IIa}) \\
\text { or severe calcification and increase of velocity } \geq 0.3 \mathrm{~m} / \mathrm{s} \\
\text { per year (IIa) } \\
\text { - For PS: } \\
\circ \text { Reduced RVEF or RV dilatation or RV failure } \\
\text { - For AR: } \\
\circ \mathrm{EF}<50 \% \\
\text { - } \mathrm{EF}>50 \% \text { and LVEDD }>70 \mathrm{~mm}, \mathrm{LVESD}>50 \mathrm{~mm} \\
\circ \text { reduced RVEF or RV dilatation or RV failure }\end{array}$ \\
\hline & & & Symptoms & Consider reoperation \\
\hline $\mathrm{V}$ (reoperation) & \multicolumn{4}{|c|}{ Status after reoperation } \\
\hline
\end{tabular}

At 5, 10, 15, and 20 years after the operation freedom from autograft and/or homograft reoperation was $97.4 \% \quad(95 \% \quad$ CI, $96.1 \%-98.6 \%), \quad 93.7 \% \quad(95 \% \quad$ CI, $91.6 \%-95.8 \%), 90.2 \%(95 \%$ CI, $87.2 \%-93.3 \%)$, and $85.9 \% \quad(95 \% \quad$ CI, $80.2 \%-92.0 \%$; Figure 2$)$. The freedom from autograft reoperation was $98.5 \%$ (95\% CI, 97.6\%-99.5\%), $96.4 \% \quad(95 \% \quad$ CI, $\quad 94.9 \%-98.0 \%)$, $94.3 \%(95 \%$ CI, $92.0 \%-96.6 \%)$, and $89.8 \%(95 \%$ CI, $84.3 \%-95.7 \%$ ), and the freedom from homograft reoperation was $98.3 \%$ (95\% CI, 97.3\%-99.4\%), 96.5\% (95\% CI, 95.0\%-98.1\%), 93.7\% (95\% CI, 91.2\%$96.3 \%$ ) and $91.0 \%(95 \% \mathrm{CI}, 86.3 \%-96.0 \%)$ at 5,10 , 15 , and 20 years, respectively (Figure 3 ). The 28 autograft reoperations were due to endocarditis in 9 patients and regurgitation in 19 patients whereas the 29 homograft reoperations were due to endocarditis in 13 patients, stenosis in 10 , regurgitation in 5 , and combined lesion in 1 patient. Ten patients needed reoperation on autograft as well as homograft.

There was no significant difference in time to autograft reoperation between tricuspid and bicuspid valves $(P=.119)$. There was no root dilatation mandating a reoperation. Five patients received a transcatheter pulmonary valve intervention. None of the potential risk factors for autograft reoperation (annulus diameter, preoperative aortic regurgitation, annulus reinforcement, sinotubular junction reinforcement, BAV type) and for homograft reoperation (age, blood type mismatch) achieved statistical significance.

\section{Function of "Ross Valves"}

Figure 4 shows autograft function over time with a slight increase of aortic regurgitation grade I and a decrease in the group "less than grade I" in the second decade. The 


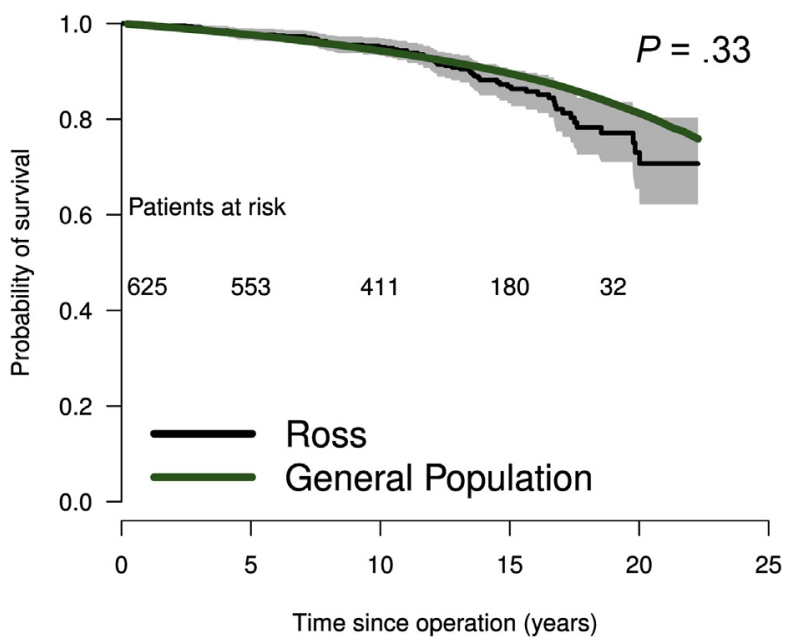

FIGURE 1. Late survival curve of the subcoronary Ross population and the age- and gender-matched general population. Only patients with follow-up $>30$ days were included.

homograft regurgitation grade I increased and "less than grade I" decreased over time and a slight increase in mean pressure gradient across the right ventricular outflow tract could be observed (Figure 4). Patients with preoperative pure aortic regurgitation tended to develop more aortic regurgitation over time compared with patients with preoperative aortic stenosis (Figure E1). The BAV type ${ }^{17}$ had no influence on developing aortic regurgitation over time.

\section{Morbidity}

At the time point of 15 years the freedom from stroke and noncerebral embolic event were $98.3 \% \quad(95 \% \quad \mathrm{CI}$, $97.1 \%-99.5 \%$ ) and $99.6 \%$ (95\% CI, 99.0\%-100\%), respectively. The 15-year freedom from autograft and homograft endocarditis was $93.8 \%(95 \% \mathrm{CI}, 91.4 \%$ $96.3 \%$ ). Eleven of the 30 endocarditis patients were successfully treated conservatively and 19 needed

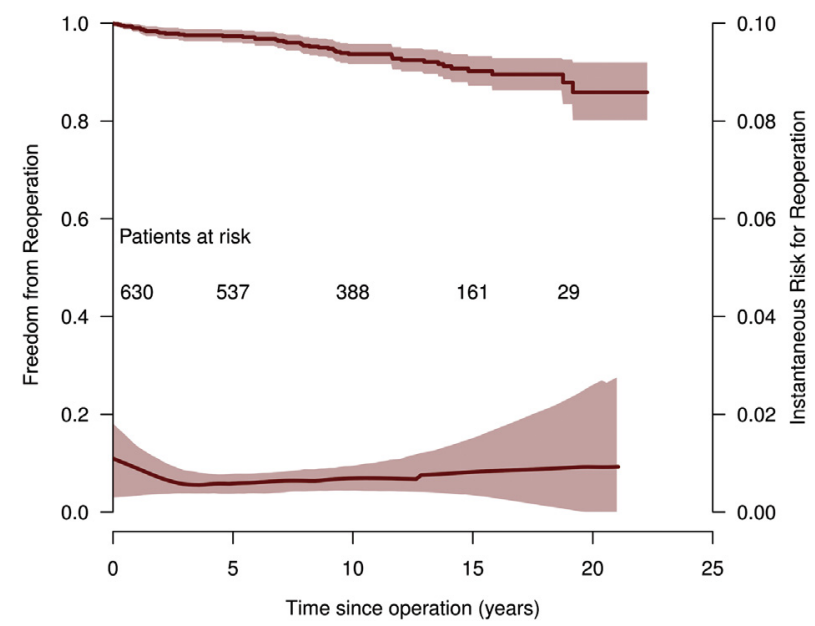

FIGURE 2. Freedom from reoperation and instantaneous risk for reoperation. reoperation. At 15 years the freedom from new-onset of atrial fibrillation was $87.3 \%$ (95\% CI, 84.0\%-90.8\%) and the freedom from major bleeding events was $97.8 \%$ (95\% CI, 96.5\%-99.1\%), whereas 5 of the 14 bleeding events occurred in patients receiving coumarin therapy.

\section{Valve Performance Classification}

Figure 5 shows the probability of VPCs with time, showing a constant decrease of VPC I, an increase of VPC II until 15 years, and an increase of VPC III in the second decade with a probability at 20 years of being in group I to IV of $5 \%, 74 \%, 19 \%$, and $1 \%$, respectively.

\section{DISCUSSION}

The survival after the subcoronary Ross procedure seems to be comparable with the normal life expectancy of the general population continuing the excellent results published previously for the first decade ${ }^{18}$ and confirming the results of other groups. ${ }^{7,9,10,23-26}$ The original subcoronary Ross technique has the advantage of warranting a natural external reinforcement of the pulmonary autograft protecting against later dilatation and preserving almost normal root dynamics in contrast to the widely used freestanding root technique., ${ }^{7,27}$ Whether this or other preservation of near normal root dimensions and dynamics using root reinforcement adds to the excellent survival remains speculative and needs further evaluation. ${ }^{26}$

Furthermore, it must be taken into consideration that these are selected patients. Most of them had normal ejection fraction as a surrogate for normal left ventricular function before the procedure. Nevertheless, these patients had for several years the burden of hemodynamic compromise, which could have had also some adverse myocardial sequelae leading to some kind of cardiac dysfunction. Maybe after longer follow-up times less favorable survival will surface, which needs to be evaluated. Figure 1 shows that after 15 years the probability of survival starts to decline more in the Ross patients compared with normal, which was also observed in a recently published 25 -year longitudinal study. ${ }^{13}$ However, the close follow-up could also have had a significant influence on the favorable survival outcome because conservative treatment support and surgical intervention were performed without delay.

The freedom from reoperation after the Ross procedure seems to be more steady even after 10 years in contrast to patients with a bioprosthesis with the rate of reoperation accelerating after 9 to 10 years. ${ }^{28}$ The linearized occurrence rate was $0.6 \%$ per patient-year. Interestingly, 19 patients needed a reoperation not from hemodynamic consideration but because of endocarditis. The risk of reoperation due to endocarditis was $0.26 \%$ per patient-year, therefore, we advise our patients to be careful to apply endocarditis prophylaxis more liberally than advocated by the recent guidelines, especially in case of depressed immunological 

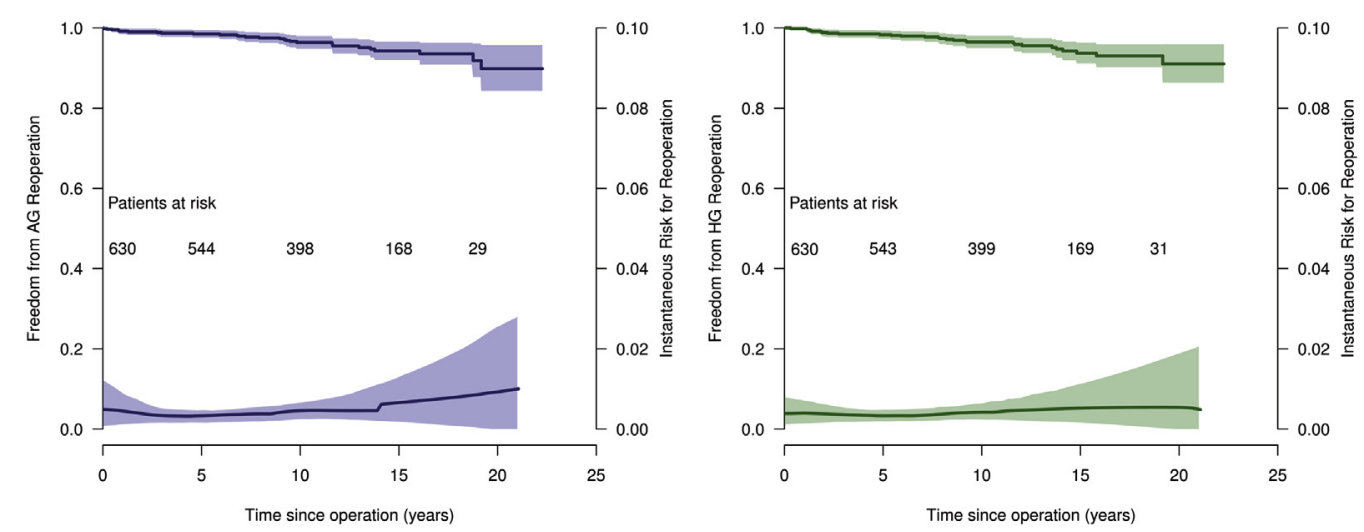

FIGURE 3. Left: freedom from autograft $(A G)$ reoperation and instantaneous risk for AG reoperation. Right: freedom from homograft $(H G)$ reoperation and instantaneous risk for $\mathrm{HG}$ reoperation.

resistance. Five patients underwent transcatheter intervention of a dysfunctional pulmonary homograft. One of these patients died during the procedure. Especially the risk for occluding nearby coronary arteries must be considered before the intervention. Nevertheless the reoperation rate can probably be reduced if this technique is applied more liberally as an alternative surgery. A recent study showed comparable midterm outcome after transcatheter and surgical homograft replacement. ${ }^{29}$ Longer follow-up time is also needed to evaluate whether the risk of reoperation increases in the third decade after the procedure. Especially in patients with previous aortic regurgitation in contrast to those with aortic stenosis we found an increase of autograft regurgitation over time (Figure E1), indicating that these patients might be at higher risk for reoperation. Also there was a slight decline of homograft sufficiency over time, potentially increasing the risk of more reoperations in the third decade, whereas the transhomograft pressure gradient increased only slightly without clinical significance (Figure 4). Probably, newer techniques of homograft preservation like decellularization could improve the results. ${ }^{30}$ Other not yet significant risk factors for reoperation like annulus diameter, reinforcement techniques, and bicuspid valve type might surface as significant contributors for reoperation. We lost 1 patient during surgical reoperation ( $2.2 \%$ hospital mortality), showing that this procedure can also be performed with low risk to the patients. The recently published "Ross reversal" offers an interesting new technique to preserve the autograft by retranslocating it into the pulmonary position if it failed in systemic pressure. ${ }^{31}$

\section{Why Introducing a Valve Performance Classification?}

With the increasing number of different valve substitutes there is a growing need for a more detailed description of the time-dependent change of postoperative valve performance other than reporting the incidence of reoperation alone. To better define "valve performance" we combined hemodynamics (from normal function over different degrees of dysfunction to reoperation) with symptoms and the clinical relevance or management in a practical classification system-VPC - including the mostly used echocardiographic items for longitudinal valve assessment and recent guidelines for management of valve disease. ${ }^{3}$ This practical and lucid VPC might help to facilitate clinical communication and comparison of different substitutes.

The long-term VPC showed that after 20 years the probability of being in VPC I is $5 \%$ and in VPC II $74 \%$, which means an unrestricted lifestyle. There is a probability of $19 \%$ after 20 years of being in VPC III, which means that there is a valve dysfunction needing close follow-up and probably in the next years a reoperation if the dysfunction or clinical deterioration accelerates or if other cardiac procedures are necessary. Together there is a reasonable perspective for a favorable VPC also for the third decade after the procedure in most patients, which is already beginning to become evident as reported by Mazine and colleagues. ${ }^{11}$ They showed excellent results even at 25 years after the Ross operation. Nevertheless these results also show that there is some increase in valve dysfunction over time albeit not clinically significant, underscoring the necessity of lifelong surveillance. The presented VPC system might become an important part of a possible future "valve outcome score" consisting of survival, VPC, and adverse events serving for an even more refined comparison of different valve substitutes in an effort to achieve valve performance as close to normal as possible, the ultimate goal of surgery.

\section{CONCLUSIONS}

We found that up to 22 years the subcoronary Ross procedure provides excellent results with near normal survival, a constant risk of reoperation of $0.6 \%$ per patient-year, and most patients in VPC I and II. BAV and preoperative aortic regurgitation did not increase the risk of reoperation. 

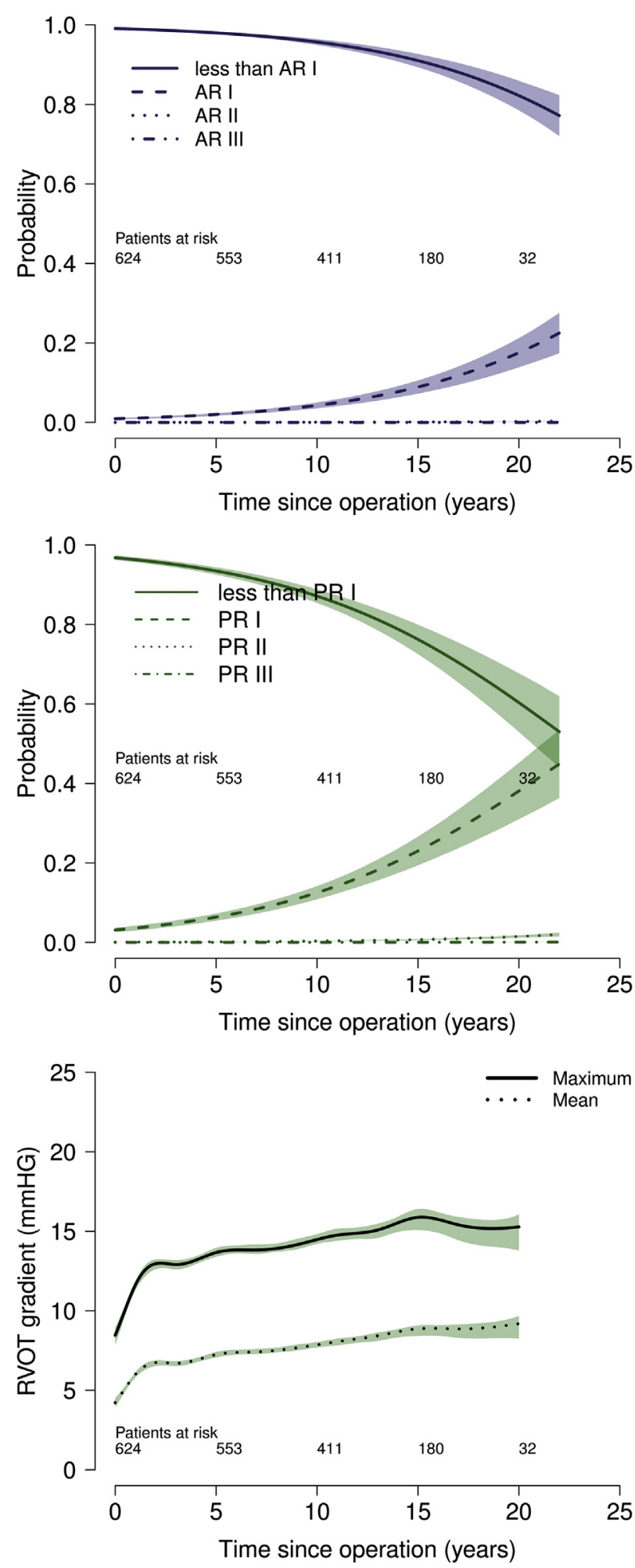

FIGURE 4. Top: probability of developing aortic regurgitation over time considering patients who are alive. Middle: probability of developing pulmonary regurgitation over time considering patients who are alive. Bottom: mean and maximum right ventricular outflow tract gradient over time. $A R$, aortic regurgitation; $P R$, pulmonary regurgitation; $R V O T$, right ventricular outflow tract.

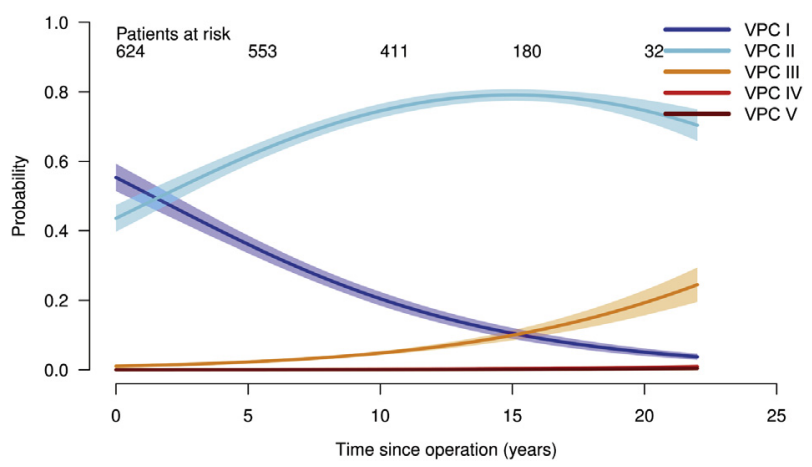

FIGURE 5. Probability of developing the 5 valve performance classes over time considering patients who are alive. $V P C$, Valve performance class.

Preoperative aortic stenosis showed better valve function in the long term. The suggested VPC emerged as a practical concept for outcome analysis with the probability of $79 \%$ being in the favorable class I or II at 20 years.

\section{Limitation}

This study has all of the shortcomings of an observational, nonrandomized investigation. However, we gathered the clinical and echocardiographic data on a prospective routine follow-up basis with almost complete follow-up in all patients. Furthermore, these patients represent a selected group, thus the comparability with other valve substitutes should be restricted to this issue.

The VPC does not include valve-related death, because it is very difficult without autopsy to know whether a death is really valve-related or from other causes, and furthermore, autopsies are rare. The same holds true for valve-related events, such as stroke and bleeding. There is a natural incidence of stroke related to nonvalvular embolism in the older population, which might compete with the risk of pure valve-related stroke.

In addition, the different causes of valve dysfunction such as structural and nonstructural dysfunction or endocarditis and thrombosis were not included in our VPC to keep it practical and lucid and because most of these items will result more or less in hemodynamic echocardiographic sequelae, which finally determine the VPC. Probably in the future these items could be included in a more sophisticated "valve outcome score" to have even more fine-tuned data as the basis for benchmark comparison of different valve substitutes after the ideal maxim of treatment, that is the individual approach to aortic valve disease.

\section{Conflict of Interest Statement}

Authors have nothing to disclose with regard to commercial support.

The authors thank Mrs Martina Schröder for her excellent secretarial support. 


\section{References}

1. Lancellotti P, Tribouilloy C, Hagendorff A, Moura L, Popescu BA, Agricola E, et al. European Association of Echocardiography recommendations for the assessment of valvular regurgitation. Part 1: aortic and pulmonary regurgitation (native valve disease). Eur J Echocardiogr. 2010;11:223-44.

2. Baumgartner H, Hung J, Bermejo J, Chambers JB, Edvardsen T, Goldstein S, et al. Recommendations on the echocardiographic assessment of aortic valve stenosis: a focused update from the European Association of Cardiovascular Imaging and the American Society of Echocardiography. J Am Soc Echocardiogr. 2017:30:372-92.

3. Baumgartner H, Falk V, Bax JJ, De Bonis M, Hamm C, Holm PJ, et al. 2017 ESC/ EACTS guidelines for the management of valvular heart disease. Eur Heart $J$ 2017;38:2739-91.

4. Andreas M, Wiedemann D, Seebacher G, Rath C, Aref T, Rosenhek R, et al. The Ross procedure offers excellent survival compared with mechanical aortic valve replacement in a real-world setting. Eur J Cardiothorac Surg. 2014;46:409-13; discussion 413-4.

5. Mazine A, El-Hamamsy I, Ouzounian M. The Ross procedure in adults: which patients, which disease? Curr Opin Cardiol. 2017;32:663-71.

6. El-Hamamsy I, Bouhout I. The Ross procedure: time for a hard look at current practices and a reexamination of the guidelines. Ann Transl Med. 2017;5:142.

7. Sievers HH, Stierle U, Charitos EI, Takkenberg JJ, Horer J, Lange R, et al. A multicentre evaluation of the autograft procedure for young patients undergoing aortic valve replacement: update on the German Ross Registry. Eur J Cardiothorac Surg. 2016;49:212-8.

8. Sievers HH, Hanke T, Stierle U, Bechtel MF, Graf B, Robinson DR, et al. A critical reappraisal of the Ross operation: renaissance of the subcoronary implantation technique? Circulation. 2006;114:I504-11.

9. El-Hamamsy I, Eryigit Z, Stevens LM, Sarang Z, George R, Clark L, et al. Longterm outcomes after autograft versus homograft aortic root replacement in adults with aortic valve disease: a randomised controlled trial. Lancet. 2010;376: 524-31.

10. Ouzounian M, Mazine A, David TE. The Ross procedure is the best operation to treat aortic stenosis in young and middle-aged adults. J Thorac Cardiovasc Surg. 2017; 154:778-82.

11. Mazine A, David TE, Rao V, Hickey EJ, Christie S, Manlhiot C, et al. Long-term outcomes of the Ross procedure versus mechanical aortic valve replacement: propensity-matched cohort study. Circulation. 2016;134:576-85.

12. Skillington PD, Mokhles MM, Takkenberg JJ, Larobina M, O'Keefe M, Wynne R, et al. The Ross procedure using autologous support of the pulmonary autograft: techniques and late results. J Thorac Cardiovasc Surg. 2015;149:S46-52.

13. Martin E, Mohammadi S, Jacques F, Kalavrouziotis D, Voisine P, Doyle D, et al Clinical outcomes following the Ross procedure in adults: a 25-year longitudinal study. J Am Coll Cardiol. 2017;70:1890-9.

14. Hanke T, Stierle U, Boehm JO, Botha CA, Matthias Bechtel JF, Erasmi A, et al. Autograft regurgitation and aortic root dimensions after the Ross procedure: the German Ross registry experience. Circulation. 2007;116:I251-8.

15. Charitos EI, Hanke T, Stierle U, Robinson DR, Bogers AJ, Hemmer W, et al. Autograft reinforcement to preserve autograft function after the ross procedure: a report from the German-Dutch Ross registry. Circulation. 2009;120: S146-54.
16. Nishimura RA, Otto CM, Bonow RO, Carabello BA, Erwin JP III, Guyton RA, et al. 2014 AHA/ACC guideline for the management of patients with valvular heart disease: a report of the American College of Cardiology/American Heart Association task force on practice guidelines. J Thorac Cardiovasc Surg. 2014; 148:e1-132.

17. Sievers HH, Schmidtke C. A classification system for the bicuspid aortic valve from 304 surgical specimens. J Thorac Cardiovasc Surg. 2007;133:1226-33.

18. Sievers HH, Stierle U, Charitos EI, Hanke T, Gorski A, Misfeld M, et al. Fourteen years' experience with 501 subcoronary Ross procedures: surgical details and results. J Thorac Cardiovasc Surg. 2010;140:816-22. 22.e1-5.

19. Sievers HH, Stierle U, Mohamed SA, Hanke T, Richardt D, Schmidtke C, et al. Toward individualized management of the ascending aorta in bicuspid aortic valve surgery: the role of valve phenotype in 1362 patients. J Thorac Cardiovasc Surg. 2014; 148:2072-80

20. Duebener LF, Stierle U, Erasmi A, Bechtel MF, Zurakowski D, Bohm JO, et al Ross procedure and left ventricular mass regression. Circulation. 2005;112 I415-22.

21. Perry GJ, Helmcke F, Nanda NC, Byard C, Soto B. Evaluation of aortic insufficiency by Doppler color flow mapping. J Am Coll Cardiol. 1987:9:952-9.

22. Clark TG, Altman DG, De Stavola BL. Quantification of the completeness of follow-up. Lancet. 2002:359:1309-10.

23. David TE, David C, Woo A, Manlhiot C. The Ross procedure: outcomes at 20 years. J Thorac Cardiovasc Surg. 2014;147:85-93.

24. Costa FD, Colatusso DF, Balbi Filho EM, Marchetti R, Ferreira AD, Costa MB, et al. 20 years experience with the Ross operation in middle-aged patients: the autologous principle is still alive. Interact Cardiovasc Thorac Surg. 2017;24:348-54.

25. Karaskov A, Sharifulin R, Zheleznev S, Demin I, Lenko E, BogachevProkophiev A. Results of the Ross procedure in adults: a single-centre experience of 741 operations. Eur J Cardiothorac Surg. 2016;49:e97-104.

26. Burkhart HM, Thompson JL, Mir A. The Ross operation: are we doing enough? J Thorac Cardiovasc Surg. 2017;154:783-4.

27. Luciani GB, Lucchese G, De Rita F, Puppini G, Faggian G, Mazzucco A. Reparative surgery of the pulmonary autograft: experience with Ross reoperations. Eur J Cardiothorac Surg. 2012;41:1309-14; discussion 1314-5.

28. Richardt D, Hemmer W, Moritz A, Hetzer R, Gorski A, Franke UF, et al. Agerelated reoperation rate after the Ross procedure: a report from the German Ross registry. J Heart Valve Dis. 2015;24:220-7.

29. Alassas K, Mohty D, Clavel MA, Husain A, Hijji T, Aljoufan M, et al. Transcatheter versus surgical valve replacement for the failed pulmonary homograft in the Ross population. J Thorac Cardiovasc Surg. 2018;155:1434-44.

30. Sarikouch S, Horke A, Tudorache I, Beerbaum P, Westhoff-Bleck M, Boethig D, et al. Decellularized fresh homografts for pulmonary valve replacement: a decade of clinical experience. Eur J Cardiothorac Surg. 2016;50:281-90.

31. Hussain ST, Majdalany DS, Dunn A, Stewart RD, Najm HK, Svensson LG, et al Early and mid-term results of autograft rescue by Ross reversal: a one-valve disease need not become a two-valve disease. J Thorac Cardiovasc Surg 2018;155:562-72.

Key Words: valve performance classification, Ross procedure, subcoronary technique, long-term data, hemodynamics 


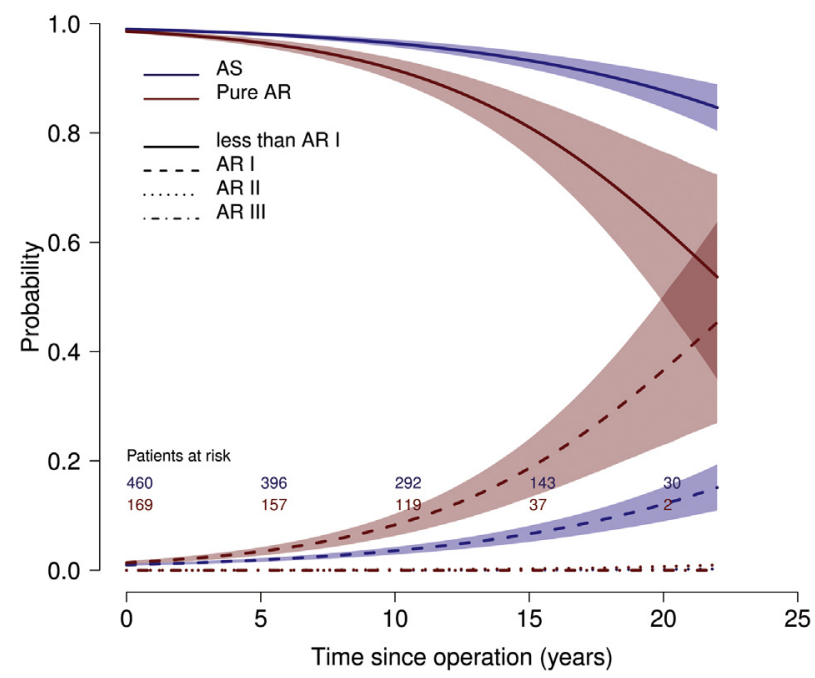

FIGURE E1. Probability of developing aortic regurgitation $(A R)$ over time in patients with preoperative pure AR and aortic stenosis $(A S)$ considering patients who are alive. 
TABLE E1. Operative details $(\mathbf{N}=630)$

\begin{tabular}{ll}
\hline & \multicolumn{1}{c}{ Value } \\
\hline Bypass time, minutes & $219.4 \pm 32.9$ \\
Cross clamp time, minutes & $182.0 \pm 30.3$ \\
Annulus reinforcement & $85(13.5)$ \\
Sinotubular junction reinforcement & $79(12.5)$ \\
Pulmonary homograft & \\
$\quad$ Donor age, y & $47.6 \pm 10.6$ \\
Blood type mismatch & $336(82.8)$ \\
$\quad$ Unknown & 224 \\
\hline
\end{tabular}

TABLE E2. Biennially completeness of echocardiographic follow-up

\begin{tabular}{lccc}
\hline Postoperative year & Patients at risk, $\mathbf{n}$ & $\begin{array}{c}\text { Completeness of } \\
\text { Number of patients with } \\
\text { echocardiography }\end{array}$ & $\begin{array}{c}\text { echocardiographic follow- } \\
\text { up, } \%\end{array}$ \\
\hline 0 to 2 & 630 & 443 & 70.3 \\
\hline 2 to 4 & 605 & 489 & 80.8 \\
\hline 4 to 6 & 571 & 496 & 86.9 \\
\hline 6 to 8 & 533 & 507 & 95.1 \\
\hline 8 to 10 & 495 & 473 & 95.6 \\
\hline 10 to 12 & 411 & 385 & 93.7 \\
\hline 12 to 14 & 316 & 293 & 92.7 \\
\hline 14 to 16 & 220 & 206 & 93.6 \\
\hline 16 to 18 & 138 & 127 & 92.0 \\
18 to 20 & 71 & 64 & 90.1 \\
\hline 20 to 22 & 32 & 28 & 87.5 \\
\hline
\end{tabular}

